\title{
SERUM ENZYME ACTIVITY IN PREMATURITY AND IN HAEMOLYTIC DISEASE OF THE NEWBORN
}

\author{
BY \\ M. BRENDA MORRIS and J. KING \\ From the Paediatric and Pathology Departments, North Lonsdale Hospital, the Barrow and Furness Hospital Group
}

(RECEIVED FOR PUBLICATION APRIL 14, 1961)

In a concurrent study of the serum activity of glutamate-oxalacetate transaminase (GO-T), glutamate-pyruvate transaminase (GP-T), lactate dehydrogenase $(\mathrm{LDH})$ and malate dehydrogenase (MDH) in normal newborn infants ranges of normal values for these enzymes have been defined (King and Morris, 1961). In the present report the activity of these enzymes in relation to neonatal jaundice and in prematurity and haemolytic disease due to rhesus and $\mathrm{ABO}$ incompatibility is investigated. This work was undertaken in an attempt to elucidate the factors in the different types of jaundice and to see what help these estimations might afford in the practical management of exchange transfusion.

\section{Methods and Material}

The biochemical techniques used in this study were those employed in the establishment of normal values for the neonatal period and reported elsewhere.

Except in very occasional cases the blood samples were obtained by scalp venepuncture.

Prematurity. Twenty-one babies defined by a birth weight of $5 \mathrm{lb} .8 \mathrm{oz}$. or under, irrespective of gestation period, had one or more enzyme estimations during the first week of life, and of these, seven also had enzyme estimations on the cord blood.

Sixteen babies had more than one estimation of any one enzyme, excluding cord blood values, and nine babies each had one exchange transfusion for hyperbilirubinaemia. The criterion for performing enzyme estimations was the clinical necessity for bilirubin estimation as suggested by an icterometer reading of 3 (Gosset, 1960). There are thus no premature babies in this group whose bilirubin levels remained low, excluding cord blood values.

Haemolytic Disease of the Newborn. (a) Anti-Rh: nine babies of which all had one or more exchange transfusions. Eight of the nine babies had three or more estimations of one or more enzymes. (b) Anti-A: 12 babies including one set of twins of which five had one or more exchange transfusions. Ten of these babies had three or more estimations of one or more enzymes.
The criteria for the diagnosis of haemolytic disease anti-A were as follows:

(i) Appearance of clinical jaundice within 24 hours of birth.

(ii) Mother found to be blood group $\mathrm{O}$, and baby blood group A.

(iii) Negative Coombs' test on baby's blood. (This was done in most, but not all, cases.)

(iv) Demonstration of immune anti-A in the mother's blood by a qualitative test for haemolysins (Dunsford and Bowley, 1955) in all cases.

It is notoriously difficult to make a firm diagnosis of haemolytic disease of the newborn due to ABO incompatibility, but the presence of clinical jaundice in the first 24 hours of life and with subsequent high bilirubin levels, together with the serological tests performed, seem adequate to make this diagnosis probable.

\section{Results}

In all three groups, we found differences in the GO-T and GP-T values compared with the normal for this age group (King and Morris, 1961). In all groups the findings are described in two parts: first, findings before exchange transfusion and where there was no transfusion, and including cord blood values, and second, findings after exchange transfusion.

\section{(1) Before Exchange Transfusion, or where there} was no Transfusion

Premature Babies. GO-T in 50 estimations: 10 were between 25 and 33 I.U.; eight were over 33 I.U. (normal range 6-25 I.U.). GP-T in 45 estimations: Five were above 11 I.U. (normal range 1-3-11 I.U.).

Haemolytic Disease Anti-Rh. Pre-transfusion figures only are given. In this group it must be remembered that all cases were exchange-transfused within the first 24 hours of birth.

GO-T in 14 estimations: Two were between 25 and 33 I.U.; four were over 33 I.U. GP-T in 15 estimations: Three were above 11 I.U. 
Haemolytic Disease Anti-A. GO-T in 27 estimations: Four were between 25 and 33 I.U.; 13 were above 33 I.U. GP-T in 27 estimations: 10 were above 11 I.U.

These points are illustrated in Figs. 1 and 2.

Table 1 is compiled from those cases in which there were three or more estimations of any one enzyme in the same baby, and illustrates the same point.

These figures demonstrate that there is an abnormality of serum enzyme activity in these three groups as compared with normal babies of the same age, and that this abnormality is only present in a very small proportion of the premature babies, but occurs in a higher proportion of babies affected by haemolytic disease of the newborn anti-Rh, and in an even higher proportion of those suffering haemolytic disease of the newborn anti-A.

(2) After Exchange Transfusion. Here it is seen that the abnormality of enzyme values is more pronounced, and that this occurs in an even higher proportion of the babies suffering from haemolytic disease anti-A.
TABLE 1

FINDINGS IN CASES NOT TRANSFUSED AND BEFORE FIRST TRANSFUSION

\begin{tabular}{l|c|c|c|c|c|c|c}
\hline & $\begin{array}{c}\text { Pre- } \\
\text { matures }\end{array}$ & Rh & ABO & $\begin{array}{c}\text { Pre- } \\
\text { matures }\end{array}$ & Rh & ABO \\
\hline GO-T 25-33 & 6 & & & GO-T $<33$ & 11 & 5 & 5 \\
GO-T $>33$ & 5 & 3 & 5 & G. & \\
GP-T $>11$ & 2 & 2 & 8 & GP-T $<11$ & 14 & 6 & 2 \\
GO-T $>33$ & 1 & 2 & 4 & GO-T $<33$ & 8 & 5 & 1 \\
GP-T $>11$ & GP-T $<11$ & & & 10 \\
LDH $>590$ & none & 2 & 2 & LDH $<590$ & 12 & 4 & 10 \\
\hline
\end{tabular}

Figures represent numbers of babies in which one or more of the respective enzyme values

Figures represent numbers of babies in which all enzyme values are normal.

16 Prematures, eight haemolytic disease anti-Rh, 10 haemolytic disease anti-A.

Table 2 gives the figures obtained in all the babies after exchange transfusion. The figures represent the number of transfusions following which the respective values were obtained. This is in contrast to Table 1 in which the figures represent cases.

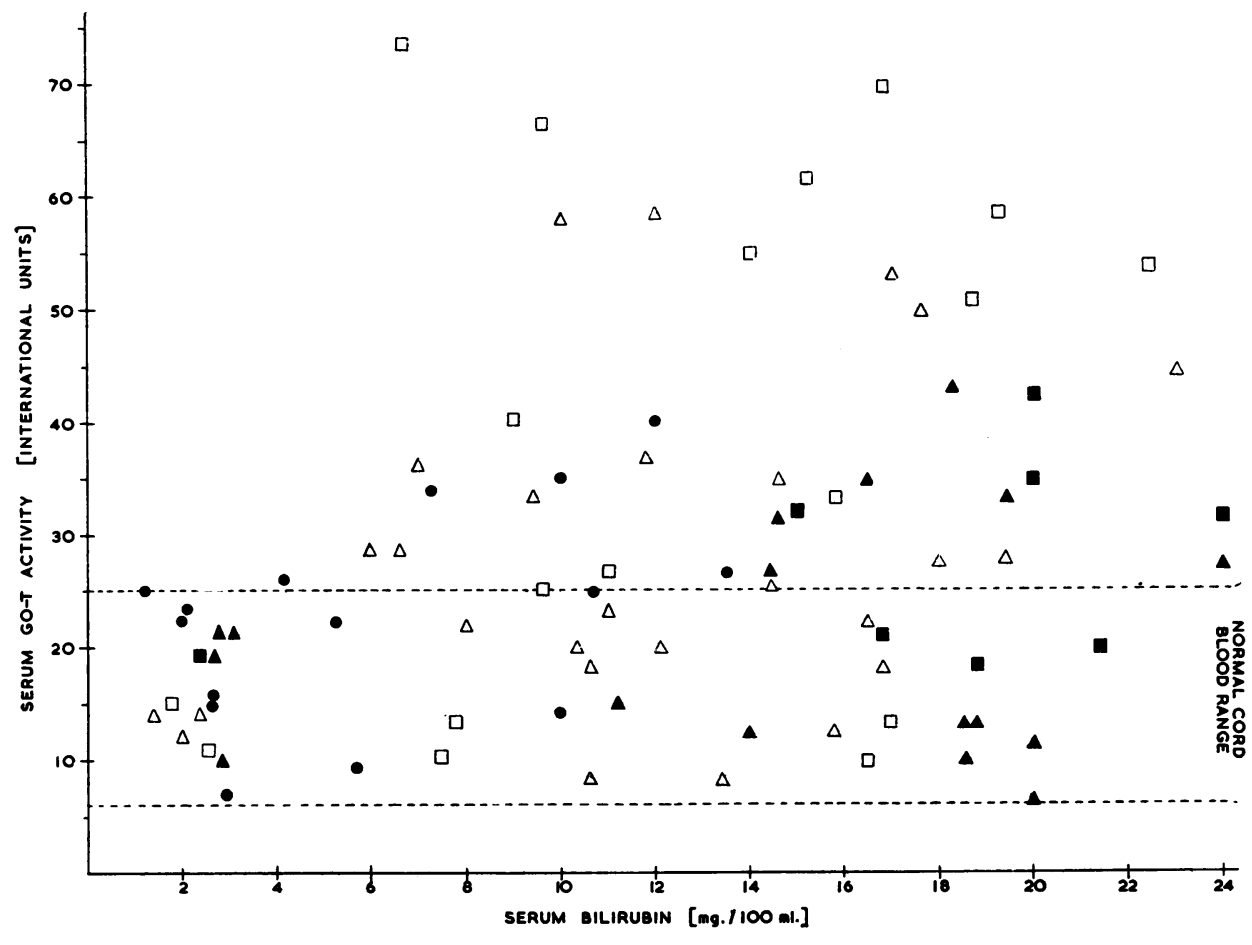

$\triangle$ Premature O ANTI-RH haEmolytic disease O ANTI-A HaEmolytic disease

FIG. 1.-Serum GO-T activity and bilirubin in prematurity and haemolytic disease. Blackened symbols indicate infants transfused later. 


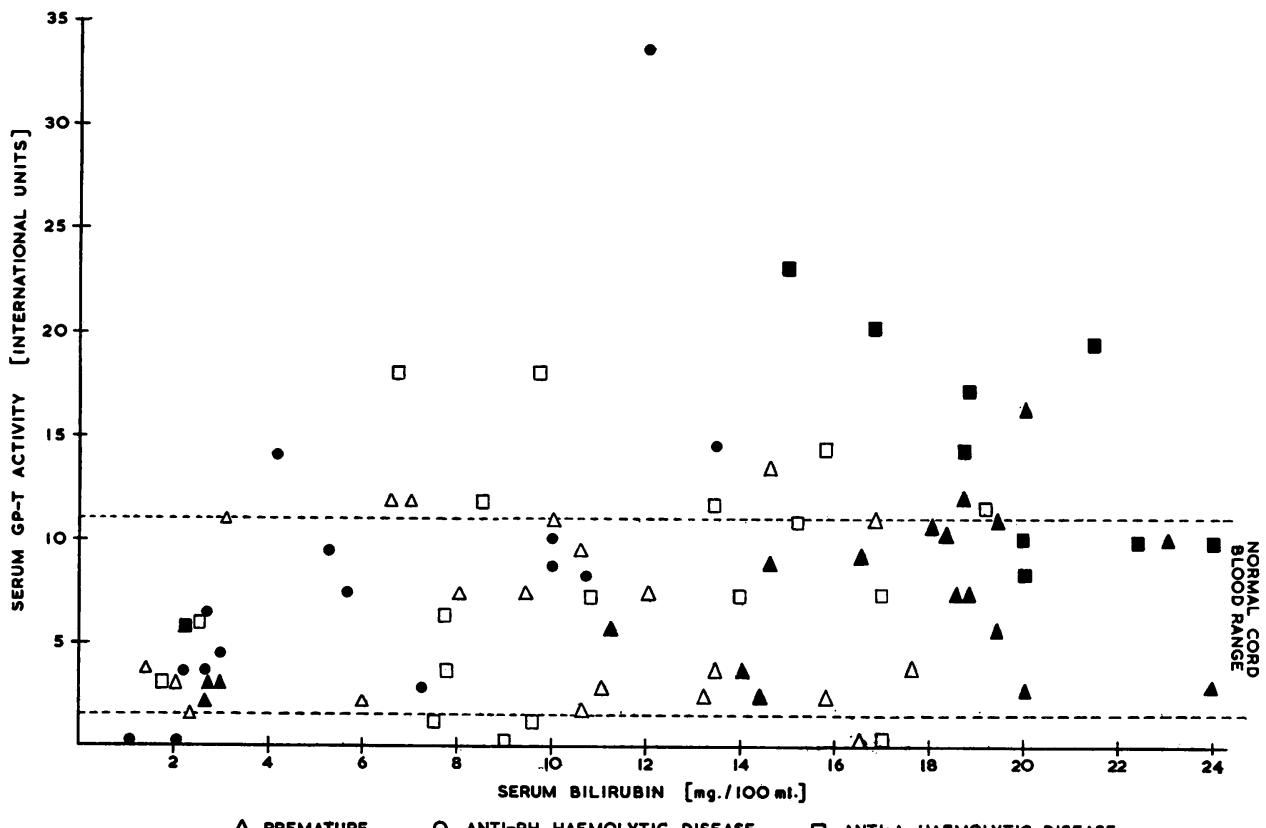

$\triangle$ PREMATURE O ANTI-RH HAEMOLYTIC DISEASE D ANTI-A HAEMOLYTIC DISEASE

FIG. 2.-Serum GP-T activity and bilirubin in prematurity and haemolytic disease. Blackened symbols indicate infants transfused later.

\section{Discussion}

Serum values for GO-T and GP-T are known to be raised in liver disease. GP-T is more sensitive than GO-T in indicating acute hepatocellular damage (Wróblewski and LaDue, 1956). It is a well-known clinical observation that in haemolytic disease the degree of jaundice does not parallel the degree of haemolysis, and is accentuated in those babies that are born prematurely. The lack of correlation between the degree of haemolysis and the degree of jaundice is striking in haemolytic disease anti-A

TABLE 2

FINDINGS AFTER TRANSFUSION

\begin{tabular}{l|c|c|c|c|c|c|c}
\hline & $\begin{array}{c}\text { Pre- } \\
\text { matures }\end{array}$ & Rh & ABO & & $\begin{array}{c}\text { Pre- } \\
\text { matures }\end{array}$ & Rh & ABO \\
\hline GO-T $>33$ & 1 & 4 & 8 & GO-T <33 & 8 & 10 & 1 \\
GP-T $>11$ & 3 & 5 & 9 & GP-T $<11$ & 6 & 10 & none \\
GO-T >33 & 1 & 4 & 8 & GO-T <33 & 5 & 9 & none \\
GP-T >11 & & & & GP-T <11 & & & \\
LDH $>590$ & 1 & 3 & 4 & LDH $<590$ & 5 & 8 & 5 \\
\hline
\end{tabular}

Figures represent numbers of transfusions following which one or more enzyme values is abnormal.

Figures represent number of transfusions following which all enzyme values are normal.

Nine prematures, nine transfusions; eight haemolytic disease anti-Rh, 16 transfusions; five haemolytic disease anti-A, nine transfusions. where jaundice can be very severe and where haemolysis is usually minimal. This phenomenon is considered to be related to the function of the liver, and these figures seem to support this view. It is not known, however, why the liver function is not satisfactory. Clinically this is not due to prematurity, although it may be accentuated by it. Again, these figures seem to illustrate this point.

The post-transfusion figures suggest that the liver dysfunction is in some cases accentuated by the transfusion. We had considerable difficulty with some of our cases whose bilirubin levels continued to rise even after transfusion of $80 \mathrm{ml}$./lb. body weight of blood, and we felt that we were not achieving a good result. This is demonstrated by the enzyme figures.

Graphs of individual babies in each group illustrate the points. Fig. 4 demonstrates the findings in a typical premature baby having an exchange transfusion, and here there were no abnormal enzyme values. Fig. 5 illustrates the findings in a case of haemolytic disease anti-Rh who had three exchange transfusions and here there are abnormal values. The washing-out effect of the transfusion is well shown. Figs. 6 and 7 illustrate findings in two cases of haemolytic disease anti-A in which exchange transfusions were carried out. Abnormal pre- and post-transfusion enzyme values are shown, 


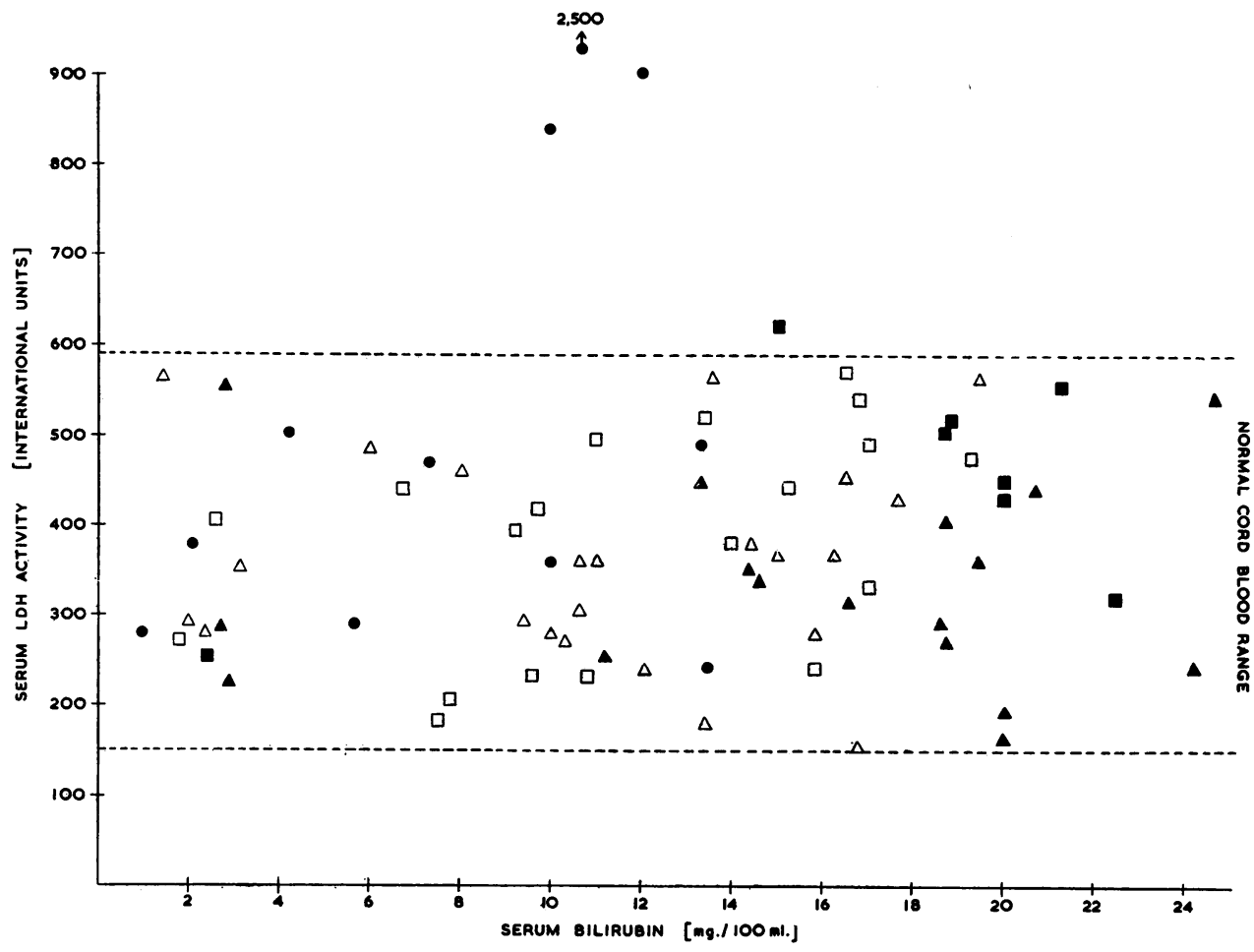

$\triangle$ premature O ANTI-RH HAEMolytic oISEASE D ANTH-A HaEmolytic disease

Fig. 3.- Serum LDH activity and bilirubin in prematurity and haemolytic disease. Blackened symbols indicate infants transfused later.

FIG. 4.-Serial enzyme activities in a $I 100$ premature male infant, birth weight 0 5 lb. 3 oz.; gestation, 36 weeks; blood group $\mathrm{O}$ Rh negative; mother's blood group $\mathrm{O} R \mathrm{R}$ negative.

- serum bilirubin;

- - - - serum GO-T activity;

-

$\ldots \ldots$ serum GP-T activity.

EXCHANGE TRANSFUSION

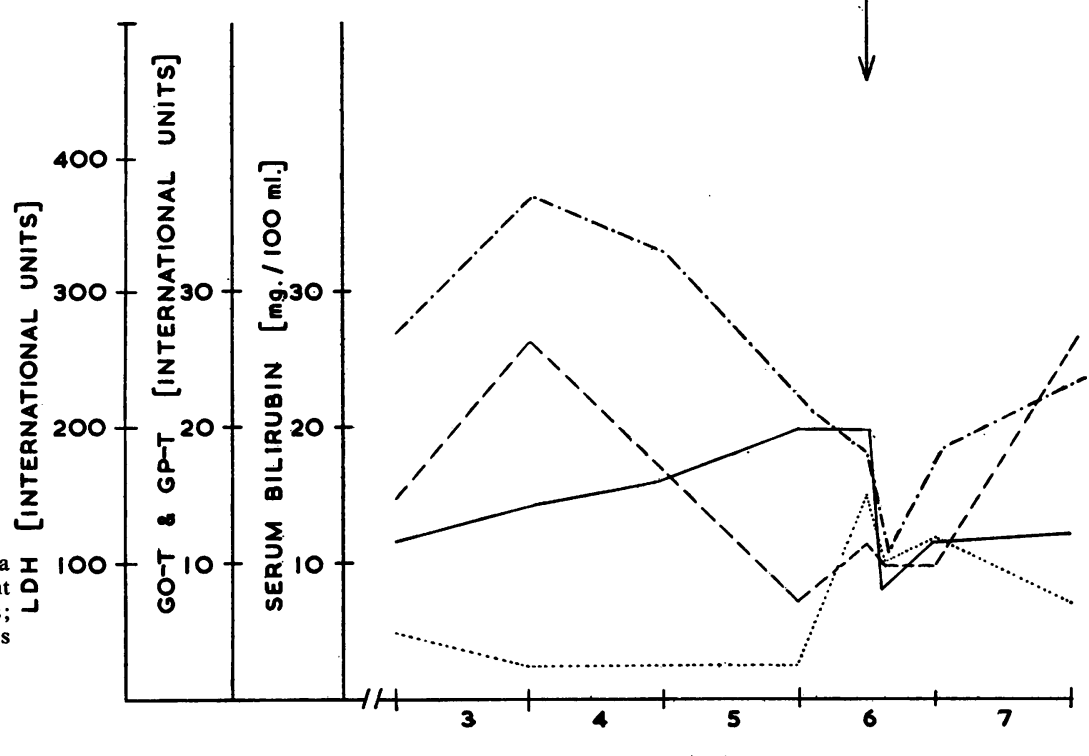

DAY OF LIFE 


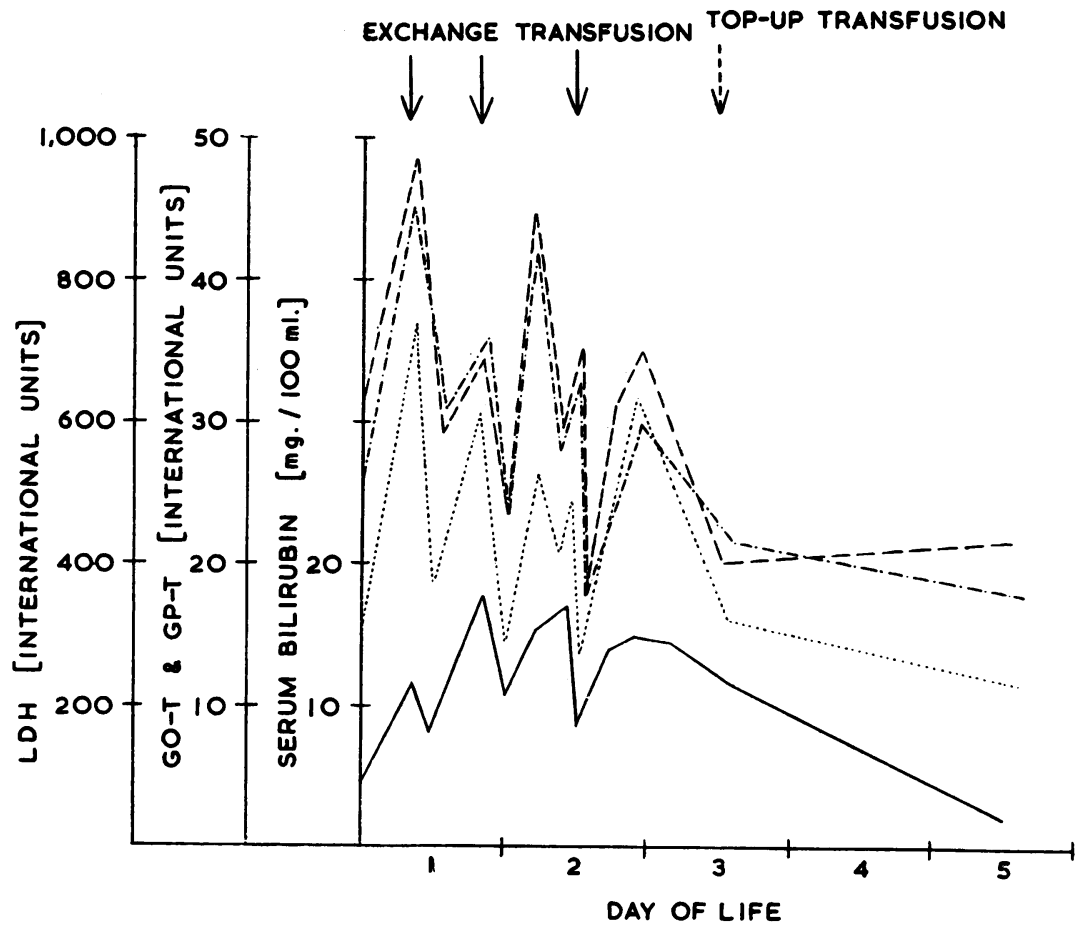

FIG. 5.-Serial enzyme activities in a male infant with anti-Rh haemolytic disease; birth weight $8 \mathrm{lb} .4 \mathrm{oz}$; gestation 38 weeks; blood group A Rh positive, mother's blood group A Rh negative. Key as for Fig. 4.

EXCHANGE TRANSFUSIONS

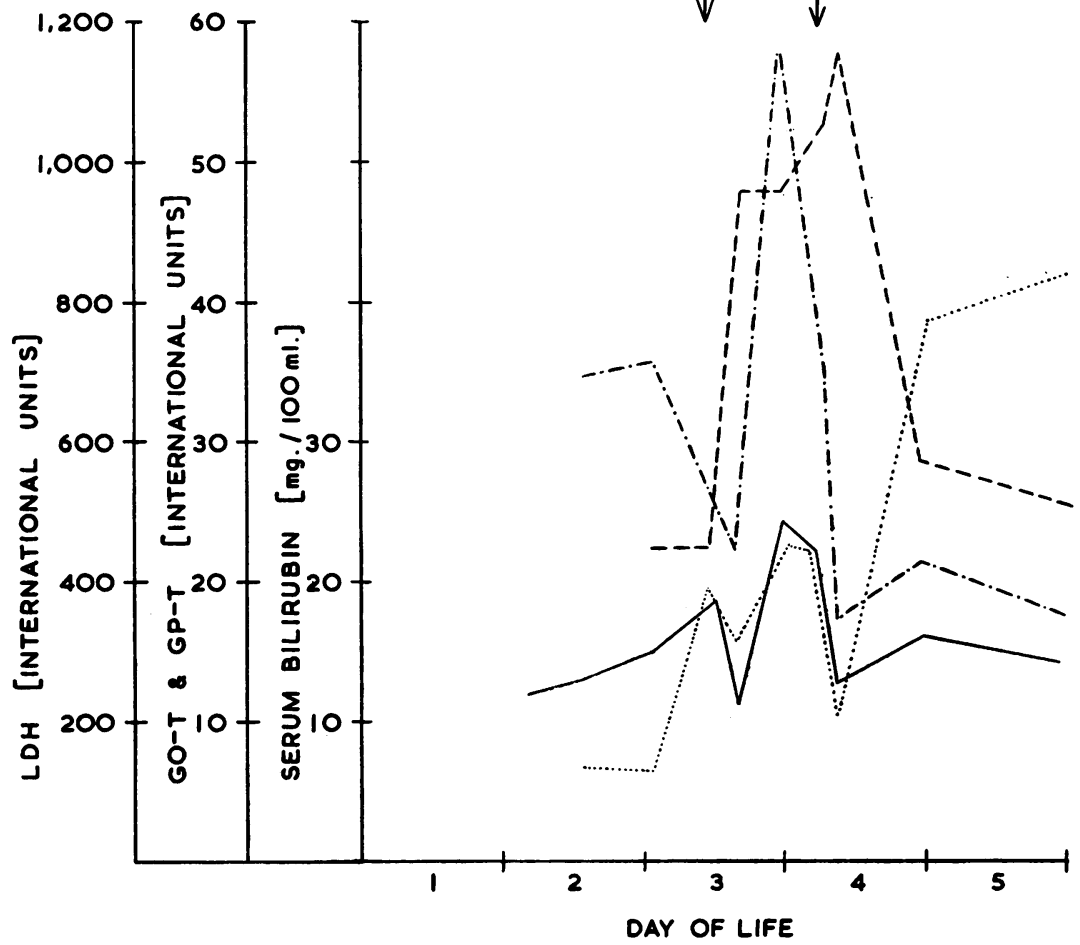

FIG. 6.-Serial enzyme activities in a female infant with anti-A haemolytic disease; birth weight $9 \mathrm{lb} .2 \mathrm{oz}$. gestation 40 weeks; blood group A $\mathrm{Rh}$ positive; mother's blood group O Rh positive.

Key as for Fig. 4. 
FIG. 7.-Serial enzyme activity in a female infant with anti-A haemolytic disease; birth weight $7 \mathrm{lb}$.; gestation 40 weeks; blood group A Rh negative, mother's blood group $\mathbf{O} \mathbf{R h}$ negative. Key as for Fig. 4.

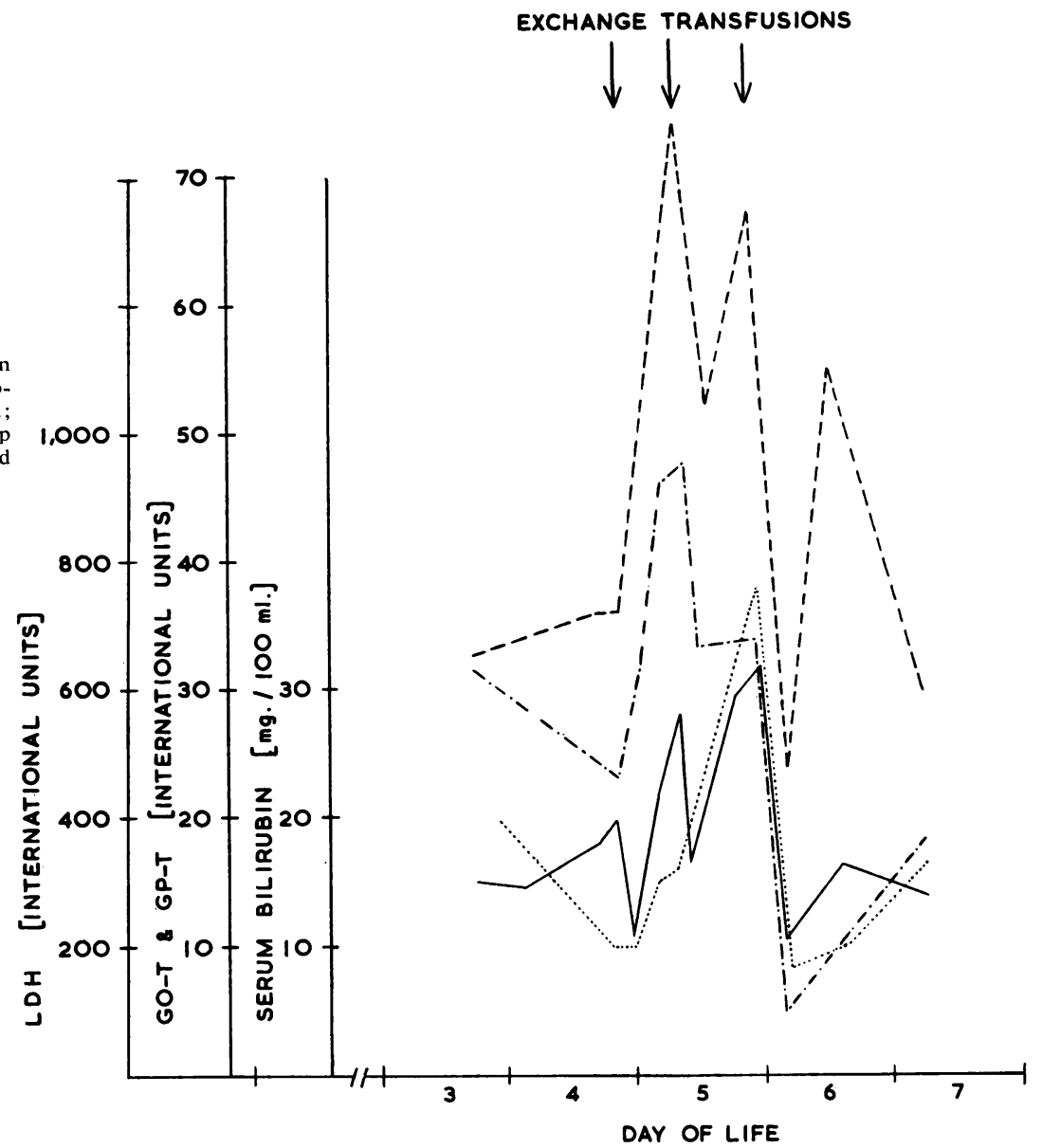

and in both cases the enzyme values are increasingly abnormal after transfusion. This is particularly marked in Fig. 7.

The haematological aspect of exchange transfusion in cases of haemolytic disease anti-A is somewhat difficult and the subject of some difference of opinion. In this group it has been the practice to use group $\mathrm{O}$ blood of the same $\mathrm{Rh}$ group as the baby without washing the cells, so that there is the possibility that immune anti-A has been present in some of the blood used. It is known that immune anti-A can occur in as high a proportion as $10 \%$ of blood donors (Walker and Dennis, 1959). It is not known whether immune anti-A was in fact present in any of the bottles used (D. Lehane, personal communication).

The liver dysfunction demonstrated in the cases of haemolytic disease, and which is so much more obvious in the cases due to anti-A immunization, may be directly related to the disease process. If this should be so it is not surprising that the liver dysfunction is accentuated by transfusion if immune anti-A is present in the transfused blood.

From the practical point of view our experience suggests that there is a good case to be made out for ensuring that the group $\mathrm{O}$ blood used for the exchange transfusion of infants suffering from haemolytic disease anti-A is free from immune anti-A.

Lactate Dehydrogenase and Malate Dehydrogenase. In all groups there were some $\mathrm{LDH}$ and MDH values above normal. The activity of these enzymes may be elevated in liver disease, but more particularly in haemolysis of which this is a very sensitive index. The raised figures which we 
obtained in some cases in this investigation appeared to be related to haemolysis in haemolytic disease and were non-contributory in relation to liver function. We do not think, therefore, that the estimation of these enzymes is of any value in the conditions under consideration. Fig. 3 shows LDH values in the three groups under discussion. MDH activity so closely paralleled LDH values in all cases that it has not been treated separately in this study.

\section{Summary}

(1) GO-T, GP-T, LDH and MDH have been estimated in a group of premature babies, and a group of babies suffering from haemolytic disease anti-Rh, and anti-A, with particular reference to liver function. LDH estimation has not been found to be of value in this respect.

(2) Abnormally high values for GO-T and GP-T have been found in a small proportion of the premature group, in a slightly larger proportion of the anti-Rh group, and in an even larger proportion of the anti-A group. A tentative suggestion is made that the liver dysfunction in haemolytic disease anti-A is related to the disease process.

(3) Even more marked abnormality of the enzyme values occurs after exchange transfusion in the anti-A group. It is postulated that this may be related to immune anti-A in the donor blood. These findings suggest that every effort should be used to see that the group $O$ blood used for exchange transfusion in these cases is free from immune anti-A.

(4) No value attaches to the estimation of $\mathrm{LDH}$ or MDH activity in the conditions studied.

We are indebted to Dr. J. E. Horrocks and Dr. J. Ward for much helpful advice and criticism and to Mrs. Mary Robinson for secretarial work. Our grateful thanks are also due to the house surgeons and nursing staff at Risedale Maternity Hospital and the technical staff of the Group Pathology Laboratory, without whose willing co-operation this work could not have been undertaken.

\section{REFERENCES}

Dunsford, I. and Bowley, C. C. (1955). Techniques in Blood Grouping, p. 152. Oliver and Boyd, Edinburgh.

Gosset, I. H. (1960). A perspex icterometer for neonates. Lancet, $1,87$.

King, J. and Morris, M. B. (1961). Serum enzyme activity in the normal newborn infant. Arch. Dis. Childh., 36, 604.

Walker, C. B. V. and Dennis, H. G. (1959). Anti-A haemolysin in group $\mathrm{O}$ blood donors. An East Anglian survey. Brit. med. J., 2, 1303 .

Wróblewski, F. and LaDue, J. S. (1956). Serum glutamic pyruvic transaminase in cardiac and hepatic disease. Proc. Soc. exp. Biol. (N.Y.), 91, 569. 